\title{
Effect of Metatarsus Reflexology Massage in Laparoscopic Cholecystectomy Nausea: A Randomized Clinical Trial
}

\author{
Marzieh Badakhsh ${ }^{1}$, Andishe Hamedi², Salimeh Azizi ${ }^{3}$
}

\begin{abstract}
Background: Nausea after surgery is an important complication. The incidence of this complication is expressed to be $40-75 \%$ in laparoscopy. Due to the risks of nausea following surgery, various methods are used to control it. Metatarsus reflexology is a noninvasive, well-tolerated, inexpensive, convenient, and cost-effective method for treating many diseases. The aim of this study is to identify the effect of metatarsus reflexology massage in laparoscopic cholecystectomy nausea.

Materials and methods: In this randomized clinical trial, 60 patients who were candidates for laparoscopic cholecystectomy were randomly divided into two groups. The control group received common drug therapy and the intervention group underwent foot reflexology massage for 10 minutes after common therapy. In recovery and at 6 and 12 hours after surgery, the severity of nausea, vomiting was evaluated in the two groups. The results were analyzed using independent $t$ test, Chi-square, and repeated measures analysis of variance is true.

Results: There were no significant differences between the two groups before intervention in terms of demographic characteristics including age, sex, duration of anesthesia, and severity of pain in recovery, However, during the study period (in both the intervention and control groups), the severity of nausea was decreased ( $p$ value $<0.001 ; F=245.24$ ).

Conclusion: Foot reflexology has an important role in nausea control along with other common treatments and it can be done by nurses due to low cost.

Keywords: Laparoscopic cholecystectomy, Nausea, Reflexology.

World Journal of Laparoscopic Surgery (2019): 10.5005/jp-journals-10033-1381
\end{abstract}

\section{INTRODUCTION}

Gallstone is one of the most common diseases of the gastrointestinal tract that causes biliary-colic pain by blocking the cystic duct and may cause a person to suffer from related complications, including acute cholecystitis, chronic cholecystitis, cholangitis, a fistula between the gallbladder and part of the intestine, and ultimately ileus. ${ }^{1}$

Currently, laparoscopic cholecystectomy due to fewer complications has been considered as the selected method for the treatment of acute cholecystitis. ${ }^{2}$ Although laparoscopy is a new step in surgery, it still has its own adverse effects, including more postsurgery nausea and vomiting compared with other techniques. This leads us to identify the appropriate way to control it. ${ }^{3}$ Postoperative nausea and vomiting is an important and common complication, especially in surgeries such as laparoscopy. The incidence of this complication following laparoscopic cholecystectomy is reported to be between $40 \%$ and $75 \% .4$

Nausea is referred to as the second cause of patient's discomfort and complaint. Postoperative nausea is a very bad experience for the patient; often the patient mentions it as a problem worse than pain. This complication can cause problems such as aspiration of the contents of the stomach, wound disclosure, esophageal rupture, and subcutaneous emphysema that can delay the discharge of the patient. $^{6}$

Now, for many patients who develop nausea after surgery, drugs such as dexamethasone and metoclopramide are used. These drugs cause several complications, such as extrapyramidal complications, drowsiness, hypotension, and dysphoria. ${ }^{7}$ In addition, intravenous ondansetron is used immediately after anesthesia or orally one hour after surgery, which has side effects such as headache, dizziness, constipation, dry mouth, muscle aches, urinary retention, and
${ }^{1}$ Department of Nursing, Samen Hospital, Social Security Organization, Bojnurd, Iran

${ }^{2}$ Department of Epidemiology, Shirvan Center of Higher Health Education, Imam Khomeini Hospital, North Khorasan University of Medical Sciences, Bojnurd, Iran

${ }^{3}$ Faculty of Nursing, North Khorasan University of Medical Sciences, Bojnurd, Iran

Corresponding Author: Salimeh Azizi, Faculty of Nursing, North Khorasan University of Medical Sciences, Bojnurd, Iran, Phone: +98 9374960903, e-mail: Azizi.s1990@gmail.com

How to cite this article: Badakhsh M, Hamedi A, Azizi S. Effect of Metatarsus Reflexology Massage in Laparoscopic Cholecystectomy Nausea: A Randomized Clinical Trial. World J Lap Surg 2019;12(3):116-119. Source of support: Nil

Conflict of interest: None

rash. ${ }^{8}$ Since most anti-nausea drugs have unpleasant adverse effects or are expensive, alternative treatments for this problem are being investigated. ${ }^{7}$ Among the various nonpharmacological methods, especially complementary and alternative medicine, acupressure can be used by physicians, nurses, and even patients. Nursing is one of the first professions, which has facilitated the use of complementary and alternative medicine. ${ }^{9}$

Reflexology is one of the complementary and substitute treatment that has a long history and can be used as an allembracing approach along with medical treatments. Reflexive massage is a noninvasive and simple technique that can be considered as part of nursing care in intensive units. ${ }^{10}$ Each metatarsus has more than 7,000 neurons, and experts in the field of reflexology believe that a life force or vital energy extends

() The Author(s). 2019 Open Access This article is distributed under the terms of the Creative Commons Attribution 4.0 International License (https://creativecommons. org/licenses/by-nc/4.0/), which permits unrestricted use, distribution, and non-commercial reproduction in any medium, provided you give appropriate credit to the original author(s) and the source, provide a link to the Creative Commons license, and indicate if changes were made. The Creative Commons Public Domain Dedication waiver (http://creativecommons.org/publicdomain/zero/1.0/) applies to the data made available in this article, unless otherwise stated. 
along the canals in the legs to all organs of the body, and any barrier to this flow ultimately leads to illness. Stimulating reflex points in the legs can break these dams in the path of the canal and release energy. These canals from each part of the body are linked with metatarsus through the nerverouts. According to some theories, massage can release endorphins and Enkephalin. ${ }^{11}$ Emeset showed that reflexology is effective in reducing nausea and vomiting in patients undergoing general surgery. ${ }^{12}$ Tadayon et al. showed that acupressure medicine has an effect on nausea and vomiting of pregnancy. ${ }^{13}$ Regarding the fact that nausea following laparoscopic cholecystectomy is one of the most important and common complications among other operations of general surgery, and it has many complications despite the medical interventions and with respect to the fact that metatarsus reflexology massage is an inexpensive, simple, and uncomplicated nonpharmacological intervention, the aim of this study was to determine the effect of foot reflexology massage on postoperative nausea in patients undergoing laparoscopic cholecystectomy.

\section{Materials and Methods}

The present study was an interventional (randomized clinical trial), which was performed on patients admitted for laparoscopic cholecystectomy in Imam Ali Hospital and Samen Alaemah Hospital in Bojnurd-2016. This randomized clinical trial was performed on 60 patients aged 20-60 years old under laparoscopic cholecystectomy in Bojnurd Hospitals. Sampling in this research was randomized. In this way, the researcher, referring to the surgery department of Imam Ali Hospital and Samen Alaemah, selected each patient diagnosed with a Colette Cystic and had criteria for entering the research, and selected them after random allocation, in one of the intervention and control groups. Finally, the patients were randomly divided into two groups of 30 controls and intervention. The criteria for entering the study include written consent for participation in the study, reading and writing literacy, diagnosis of cholecystitis by ultrasound, and general surgeon's opinion, ages 20-60 years, general anesthesia for operation, history of gastrointestinal disorders, lack of experience with reflective massage, not having diabetes and diabetic foot, having a healthy limb on foot, having no addiction to any substance or cigarette, the body mass index was less than 30 . Patients with neurological and postoperative complications, reluctance to continue the study, surgery for more than 2 hours, drug injection out of the prescribed anesthetic protocol, patients with nasogastric tube (NGT) after surgery and severe pain were excluded from the study. Instruments used in this study were a demographic questionnaire (age, sex, duration of anesthesia) and a list of the severity of nausea and vomiting. Visual analog scale (VAS) was used to measure and evaluate it. Through which a ruler, scaled from 0 to 10 , was provided to the patient. Zero is equivalent to no nausea and ten equal to the highest severity of nausea ( $0-3$ is mild nausea, $3-7$ moderate and more than 7 severe nausea). To assess the severity of vomiting, the following scores were used: $0-3$ mild vomiting, 3-7 moderate vomiting, more than 7 (severe vomiting). To determine the validity of the questionnaire, the content validity method was used under the guidance of the supervisors and counselors, and then five experts in the field of acupuncture and massage therapy. After considering the suggestions and necessary corrections, the final tool is used. In order to determine the validity of the method of acupressure, the first training course was conducted under the supervision of a traditional Chinese medicine specialist and then the method was applied by a researcher on a number of patients. After confirming the application of the acupressure method by the Chinese traditional medicine specialist, the researcher started. Content validity method was used to determine the validity of the visual scale of nausea and vomiting (VAS) and to determine its reliability, Cronbach's alpha test was used. This scale has also been used in various research. ${ }^{13,14}$ All patients were operated by an anesthetic team under a general anesthetic procedure and underwent one surgeon. Meanwhile, the technique and type of anesthetic drug were also controlled as a variable, which included, for all patients, anesthetic drugs: (1) Ndodone $2 \mu \mathrm{g} / \mathrm{kg}$ as a preoperative drug. (2) Fentanyl $2 \mu \mathrm{g} / \mathrm{kg}$. (3) For rapid muscular relaxation of xoxinilcholine and atherocurium at a dose of $0.5 \mathrm{mg} / \mathrm{kg}$ body weight. (4) Anesthetizing gas of iso-fluoranes was used during the operation, then $\mathrm{CO}_{2}$ gas was pressurized to $15 \mathrm{~mm} \mathrm{Hg}$ in the abdomen. The control group received only commonly used drug therapy and in intervention group in addition to commonly used drug therapy, metatarsus reflexology massage was performed. In such a way that by pushing the region of the solar network or the neural network behind the stomach underwent the foot in the center of the region, at the midpoint of the attachment of the second and third metatarsal bones, while the patient sleeping on the back, tight pressure on the area for 20 minutes (10 minutes right leg and 10 minutes left leg) was performed by Thumbs. Massage was performed at the patient's when they entrance from the recovery to the department and the patient's nausea and vomiting were measured. The severity of nausea and vomiting of patients was measured in recovery after the patient's consciousness (while the patient is completely alert) just prior to the transfer of the patient from recovery to the department, 6 hours after the surgery, and then 12 hours after the surgery. Finally, we used SPSS $_{19}$ software for analyzing the data by using independent $t$ test, Chi-square, repeated measures analysis of variance (ANOVA) at a significant level of $0.05 \%$ and $95 \%$ confidence interval (Flowchart 1).

\section{Results}

This clinical trial study was performed on 60 patients aged 20-60 years old under laparoscopic cholecystectomy referred to hospitals in Bojnurd. Patients were randomly divided into two groups of 30 subjects. The mean age of the subjects was 44.96 years. Of the studied individuals, $38.3 \%$ were women and $61.7 \%$ were men. Demographic characteristics based on the two study groups as shown in Table 1.

In the present study, as shown in Table 1, there was a significant difference between age in the two groups (in both intervention and control groups). We used the logistic regression model to eliminate the age-related confounding effect. However, in the present study, the results show that the mean pain of patients in the recovery room, was not significantly different in both groups. Also, during the study period (in both the intervention and control groups), the severity of nausea was decreased ( $p$ value $<0.001 ; F=245.24$ ). The results indicate the effect of foot reflexology massage on changes in nausea in patients after cholecystectomy $(p<0.001 ; F=67.62)$. The results of the distribution of changes in severity of nausea and vomiting in the intervention and control groups are shown in Tables 2 and 3. The results of Table 3 show that during the study period (in both the intervention and control groups), the severity of vomiting was decreased $(p<0.001 ; F=245 / 95)$. The results indicate that the effect of massage underwent the foot on changes in vomiting in patients after cholecystectomy $(p<0.001 ; F=94.11)$. 
Flowchart 1: The stages of subject selection in this clinical trial study

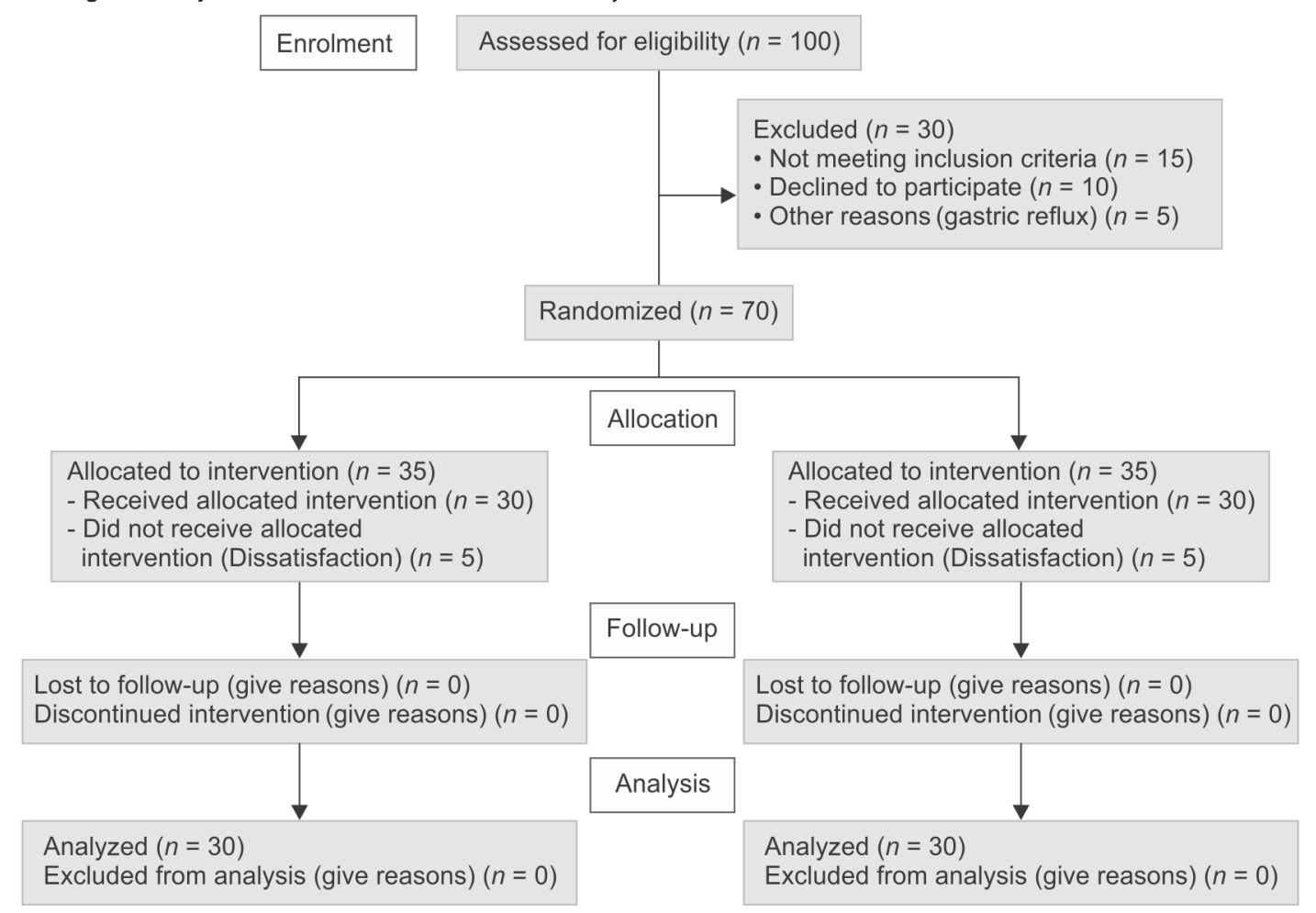

Table 1: Demographic characteristics of patients undergoing laparoscopic cholecystectomy in two groups before intervention

\begin{tabular}{|c|c|c|c|}
\hline \multirow[b]{2}{*}{ Variables } & \multicolumn{2}{|c|}{ Groups } & \multirow[b]{2}{*}{$p$ value } \\
\hline & $\begin{array}{l}M \pm S D \text { in inter- } \\
\text { vention groups }\end{array}$ & $\begin{array}{l}M \pm S D \text { in con- } \\
\text { trol groups }\end{array}$ & \\
\hline Age & $94.06 \pm 42.7$ & $86.5 \pm 47.6$ & 0.003 \\
\hline Duration of anesthesia & $37.1 \pm 5.5$ & $39.4 \pm 5.1$ & 0.11 \\
\hline $\begin{array}{l}\text { Severity of pain in } \\
\text { recovery }\end{array}$ & $5.03 \pm 0.73$ & $5.06 \pm 0.73$ & 0.17 \\
\hline \multicolumn{4}{|l|}{ Frequency } \\
\hline \multirow[t]{2}{*}{ Sex } & $16(53.3)$ & $21(70)$ & 0.18 \\
\hline & $14(46.7)$ & $9(30)$ & \\
\hline
\end{tabular}

*Significant at a level of 0.05

Table 2: Distribution of changes in severity of nausea in the intervention and control group during the study period after intervention

\begin{tabular}{|c|c|c|c|}
\hline $\begin{array}{l}\text { Severity of } \\
\text { nausea }\end{array}$ & $\begin{array}{l}M \pm S D \text { in inter- } \\
\text { vention groups }\end{array}$ & $\begin{array}{l}M \pm S D \text { in } \\
\text { control groups }\end{array}$ & $p$ value \\
\hline In recovery & $6.33 \pm 0.9$ & $6.06 \pm 0.7$ & 0.24 \\
\hline $\begin{array}{l}6 \text { hours after } \\
\text { surgery }\end{array}$ & $3.63 \pm 0.6$ & $5.7 \pm 0.6$ & $<0.001$ \\
\hline $\begin{array}{l}12 \text { hours after } \\
\text { surgery }\end{array}$ & $2.7 \pm 0.5$ & $3.5 \pm 0.6$ & $<0.001$ \\
\hline
\end{tabular}

*Significant at a level of 0.05

\section{Discussion}

In the present study, the results show that the severity of nausea and vomiting in the recovery room before the intervention in the control and experimental groups were not statistically significant.
Table 3: Distribution of changes in severity of vomiting in the intervention and control group during the study period after intervention

\begin{tabular}{lccc}
\hline $\begin{array}{l}\text { Severity of } \\
\text { vomiting }\end{array}$ & $\begin{array}{l}M \pm S D \text { in inter- } \\
\text { vention groups }\end{array}$ & $\begin{array}{l}M \pm S D \text { in } \\
\text { control groups }\end{array}$ & $p$ value \\
\hline $\begin{array}{l}\text { In recovery } \\
\begin{array}{l}6 \text { hours after } \\
\text { surgery }\end{array}\end{array}$ & $3.97 \pm 0.8$ & $5.87 \pm 0.62$ & 0.61 \\
$\begin{array}{l}12 \text { hours after } \\
\text { surgery }\end{array}$ & $2.8 \pm 0.6$ & $2.6 \pm 0.67$ & $<0.001$ \\
*Significant at a level of 0.05 & & 0.04 \\
\end{tabular}

However, during the study period (in both experimental and control groups), the severity of nausea and vomiting decreased. The results indicate that the effect of massage underwent the foot on changes in vomiting in patients after cholecystectomy. Such studies have also shown that foot massage had a dramatic effect on pain relief in patients. ${ }^{9,14}$

Nausea is one of the most common postoperative complications of laparoscopic cholecystectomy. In most cases, antinausea drugs are used to reduce this complication and each of them has its own adverse effects and high cost. Therefore, much research has been conducted to find more accessible and cheaper methods with fewer complications. One of the methods for reducing nausea is reflexology medicine, which is a part of the holistic and complementary medicine and is based on the idea of treatment through the massage of the metatarsus. This is a well-tolerated, inexpensive, and easy method and it is believed that it can improve and reduce nausea by reducing stress and improving blood flow to organs.

Various studies have evaluated the effects of reflexology on people with different conditions, and according to the present study, it has been considered effective in reducing nausea. 
For example, in the study of Choudhary et al. that was conducted on 60 patients undergoing general surgery, it was found that foot reflexology massage reduced the severity of nausea and vomiting of these patients in the intervention group, which is consistent with the results of the present study. ${ }^{12}$

In this study, the results showed that the severity of nausea significantly decreased in the first 6 hours after surgery in the intervention group ( $p$ value $<0.001$ ), which is consistent with the results of the Choudhary et al. ${ }^{12}$ In the study by Yoosefian et al. That was conducted on 37 patients undergoing chemotherapy, it was found that foot reflexology massage in the intervention group reduces the severity and frequency of vomiting within 4 hours of chemotherapy, which is consistent with the results of the present study. ${ }^{12}$ In the study of Tadayon et al. that was conducted on 100 pregnant women, it was found that foot reflexology massage is effective on improving nausea in patients, which is consistent with the results of the present study. ${ }^{13}$ The severity of nausea and vomiting in the intervention group during the 12 hours after surgery reduced compared with the control group. The study by Yoosefian also confirms this result. However, such studies had shown that reflexive massage did not have a positive effect on vomiting in the long time after surgery. ${ }^{12,14}$ It has been argued that finger pressure on the points of the reflex in the foot can affect the desired target function and causes the patient to become relaxed and recover. ${ }^{15}$ Also, there was no significant relationship between the duration of anesthesia in the two groups. Because all patients were operated by an anesthetic team under a general anesthetic procedure and were operated by one surgeon. As a result, the technique and type of anesthetic was considered as a control variable. Text book showed that increasing the duration of anesthesia can increase the incidence and severity of nausea and vomiting in patients, especially in women.

The results of this study showed that reflexology massage reduced nausea in cholecystectomy patients and it can be used as a treatment method to relieve patients' postoperative nausea along with other drug therapies.

\section{ACKnowledgments}

This is a thesis approved by Sabzevar University of Medical Science; hereby the researchers are grateful to the Research Council of Sabzevar University of Medical Science and all the patients participating in the study. This article is registered as Clinical Trial Code: IRCT2016052824487N2 and Ethics Code: IR.MEDSAB. REC.1394.176.

\section{References}

1. Hunter J, Oddsdottir M. Gallbladder and the extra hepatic billiary system. Schwartz's principles of surgery. NewYork: McGraw Hill Company; 2005.

2. Ansaloni L, Pisano M, Coccolini F, et al. 2016 WSES guidelines on acute calculous cholecystitis. World J Emerg Surg 2016;11(1):25. DOI: 10.1186/s13017-016-0082-5.

3. Park A, Lee G, Seagull FJ, et al. Patients benefit while surgeons suffer: an impending epidemic. J Am Coll Surg 2010;210(3):306-313.

4. Doyle SB. Is dexamethasone $4 \mathrm{mg}$ a more effective anti-emetic than dexamethasone $8 \mathrm{mg}$ for the prevention of early postoperative nausea and vomiting in women undergoing laparoscopic gynecological surgery? The University of Southern Mississippi; 2015.

5. Miller Ronald D. Anesthesia, 5th ed., Philadelphia: Churchil Livingston; 2000. pp. 2213-2237.

6. Thompson HJ. The management of post-operative nausea and vomiting. J Adv Nurs 1999;29(5):1130-1136. DOI: 10.1046/j.13652648.1999.00998.x.

7. Krobbuaban B, Pitakpol S, Diregpoke S. Ondansetron vs. metoclopramide for the prevention of nausea and vomiting after gynecologic surgery. Med J Med Assoc Thailand 2008;91(5):669.

8. Marthy M, Pouillart P, Pcholl S. Comparison of the 5-hydroxytryptamine (serotonin) antagonist ondansetron (GR38032F) with high-dose metoclopramide in the control of cisplatin-induced emesis. N Engl J Med 1990;322:816-821. DOI: 10.1056/NEJM199003223221205.

9. Chen H-M, Chang F-Y, Hsu C-T. Effect of acupressure on nausea, vomiting, anxiety and pain among post-cesarean section women in Taiwan. Kaohsiung J Med Sci 2005;21(8):341-350. DOI: 10.1016/ S1607-551X(09)70132-9.

10. Sadeghi Shermeh M, Bozorgzad P, Ghafourian A, et al. Effect of foot reflexology on sternotomy pain after coronary artery bypass graft surgery. Iran J Crit Care Nurs (IJCCN) 2009;2(2):51-54.

11. Ebadi A, Mahmoudi H. The effect of foot reflexology massage on the level of pain during chest tube removal after open heart surgery. Iran J Crit Care Nurs 2014;7(1):15-22.

12. Emeset SD, Promethazine M. Efficacy of reflexology in prevention of post-operative nausea vomiting.

13. Tadayon M, Salehiyan T, Abbaspour Z, et al. Comparison of the effect of acupressure and vitamin $B 6$ on the severity of nausea and vomiting in pregnancy. Med Sci J 2005;4(3):195-200.

14. Miandoab NY, Ezzati Z, Arbabi F, et al. The effect of reflexotherapy on chemotherapy-induced vomiting of. Adv Nurs Midwifery 2012;22(76):60-68.

15. Wang MY, Tsai PS, Lee PH, et al. The efficacy of reflexology: systematic review. J Adv Nurs 2008;62(5):512-520. DOI: 10.1111/j.13652648.2008.04606.x. 